\title{
SOSIALISASI TEKNIK PENYIMPANAN PRODUK HASIL TANGKAPAN LAUT DENGAN METODE BEKU DI DESA PENYAK
}

\author{
Fitri Afriani $^{1)}$, Yekti Widyaningrum ${ }^{2)}$, Widodo B. Kurniawan ${ }^{3)}$, Herman Aldila ${ }^{4)}$, Yuant \\ Tiandho ${ }^{5}$ \\ Jurusan Fisika, Universitas Bangka Belitung \\ Jl. Kampus Peradaban, Bangka, Kep. Bangka Belitung, Indonesia \\ *Corresponding Email: fitriiafriani@gmail.com
}

\begin{abstract}
ABSTRAK
Di dalam makalah ini, lokasi yang menjadi sasaran untuk kegiatan pengabdian masyarakat ini adalah Desa Penyak, Kecamataan Koba, Kabupaten Bangka Tengah. Mayoritas profesi dari masyarakat Desa Penyak adalah nelayan karena desa ini berbatasan langsung dengan Laut China Selatan. Hasil tangkapan laut di Desa Penyak cukup melimpah meliputi berbagai jenis ikan, kerang, serta rajungan. Tetapi kebanyakan masyarakat yang memasarkan hasil tangkapan laut tersebut belum menggunakan teknik-teknik penyimpanan hasil perikanan sehingga dikhawatirkan hasil tangkapan laut tersebut menurun kualitasnya. Solusi yang ditawarkan pada pengabdian kepada masyarakat ini adalah sosialisasi penyimpanan produk hasil tangkapan laut dengan metode beku. Selain itu, agar masyarakat dapat memanfaatkan secara langsung maka di dalam kegiatan ini juga dilakukan penyerahan peralatan freezer box kepada pihak Desa Penyak. Melalui proses evaluasi diketahui bahwa freezer box yang diserahkan dapat dimanfaatkan dengan baik oleh masyarakat Desa Penyak terutama untuk menyimpan berbagai produk pangan.
\end{abstract}

Kata kunci: metode beku, penyimpanan, sumber daya maritim

\section{ABSTRACT}

In this paper, the location that is targeted for community service activities is Penyak Village, Koba Sub-District, Central Bangka Regency. The majority of the profession of the Penyak Village community are fishermen because the village is directly adjacent to the South China Sea. Maritime resources in Penyak Village are quite abundant including various types of fish, shellfish and small crab. But most people who market these resources have not used techniques for storing fishery products. Therefore, it is feared that the fishery products will decline in quality. The solution offered to this community service is the socialization of frozen fishery product storage. In addition, in order for the community to directly utilize it, the freezer box equipment was provided to Penyak Village. Through the evaluation process, it is known that the freezer box provided can be utilized by Penyak Village community, especially for storing food products.

Keywords: freezing methods, storage, maritime resources

\section{Pendahuluan}

Desa Penyak merupakan salah satu desa di Kecamatan Koba, Kabupaten Bangka Tengah yang memiliki luas wilayah sekitar $75 \mathrm{~km}^{2}$ dan berbatasan langsung dengan Laut Cina Selatan seperti ditunjukkan oleh Gambar 1. Desa Penyak memiliki 14 RT dengan total jumlah penduduk sebesar 3.589 jiwa. Mayoritas mata pencaharian penduduk Desa Penyak adalah nelayan dan petani. Mayoritas hasil tangkapan nelayan di Desa Penyak diantaranya adalah kerang, kepiting, lobster, udang dan ikan. Hasil tangkapan tersebut umumnya masih dijual secara tradisional di lapak-lapak didepan rumah masyarakat yang banyak dijumpai di sepanjang jalan desa. Selain itu juga terdapat beberapa warga di Desa Penyak yang mengolah rajungan untuk dijual ke daerah luar Provinsi Kepulauan Bangka Belitung. 


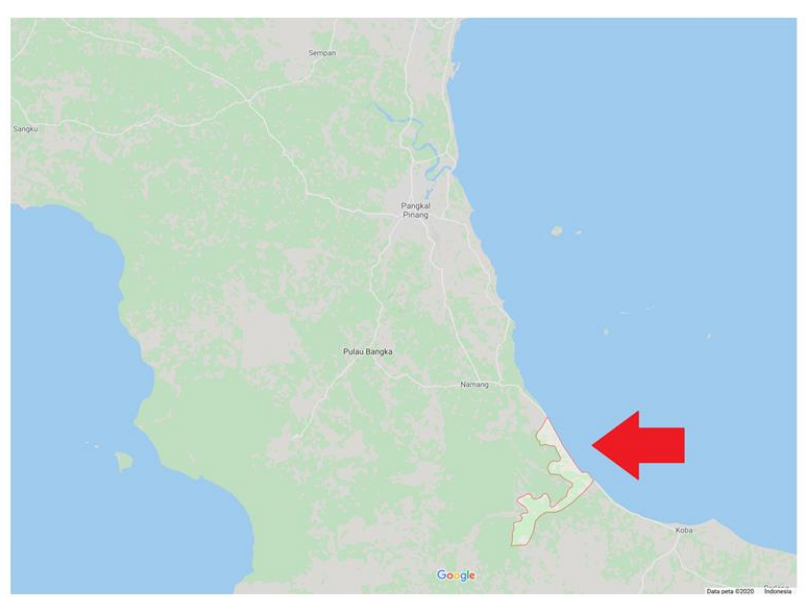

(a)

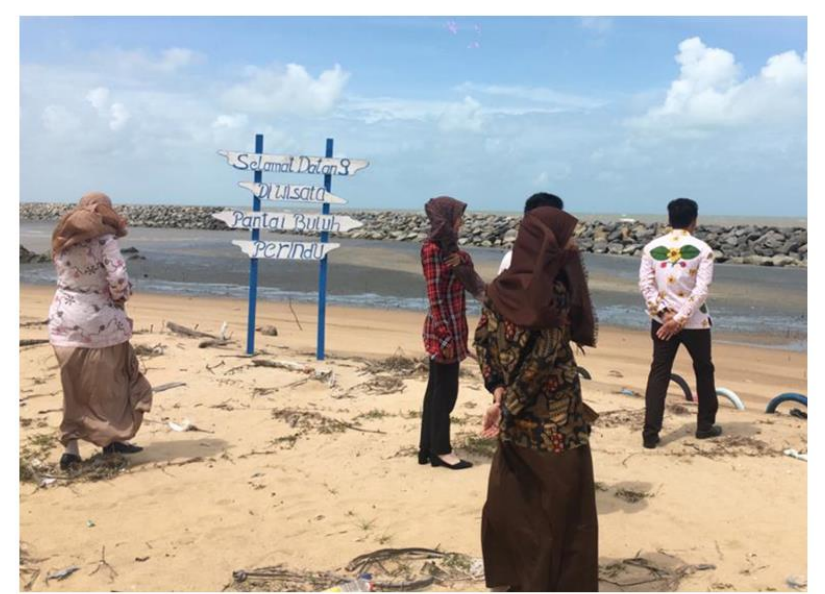

(b)

Gambar 1. (a) Lokasi Desa Penyak di Pulau Bangka (ditunjukkan panah merah); (b) laut di Desa Penyak

Permasalahan yang kerap dialami para nelayan di Desa Penyak terkait penjualan hasil tangkapan lautnya terfokus pada kualitas produk hasil laut nelayan. Karena masih melakukan penangkapan hasil laut secara tradisional, seperti menggunakan pancing dan jaring, maka hasil tangkapan mereka sangat dipengaruhi oleh musim. Hal ini menyebabkan adanya fluktuasi harga jual produk tangkapan nelayan. Pada saat musim tangkap tinggi maka harga hasil tangkapan akan jatuh dan begitu pula sebaliknya. Di sisi lain, para nelayan masih memiliki pengetahuan yang minim terkait pengolahan produk hasil laut serta cara penyimpanannya. Oleh karena itu banyak nelayan memilih untuk menjual tangkapan hasil lautnya kepada tengkulak untuk menghindari kerugian akibat menurunnya kualitas hasil tangkapan akibat pembusukan.

Langkah awal yang mungkin dilakukan untuk menjaga kestabilan harga hasil tangkapan nelayan tersebut adalah dengan pengawetan produk. Dengan memiliki pengetahuan dan teknologi terkait pengawetan hasil tangkapan maka nelayan memiliki fleksibililitas yang lebih tinggi terkait penjualannya. Salah satu metode pengawetan produk hasil laut yang telah umum digunakan adalah metode cooling (pembekuan) yang bertujuan agar tangkapan hasil laut tetap dalam kondisi segar (Darmadi, dkk., 2016; Nugroho, dkk., 2016).

Oleh karena itu, sebagai solusi untuk mengatasi permasalahan yang muncul pada nelayan di Desa Penyak maka pada program pengabdian kepada masyarakat ini dilakukan sosialisasi terkait penyimpanan hasil tangkapan dengan metode pembekuan. Hal ini bertujuan agar masyarakat nelayan di Desa Penyak memiliki wawasan yang lebih luas terkait penyimpanan hasil tangkapan laut sehingga hasil tangkapan laut yang dihasilkan dapat terjaga kualitasnya. Selain itu, pada program pengabdian kepada masyarakat ini juga dilakukan penyerahan alat penyimpanan ikan kepada Pemerintah Desa Penyak agar dapat digunakan oleh masyarakat terutama melalui Badan Usaha Milik Desa Penyak.

\section{Tinjauan Pustaka}

Pada dasarnya hasil tangkapan laut oleh para nelayan di Desa Penyak seperti ikan, kerang, udang, dan rajungan mengandung nilai gizi yang sangat tinggi (Auliya, dkk., 2015). Oleh karena itu sudah selayaknya hasil tangkapan laut tersebut memiliki nilai ekonomis yang tinggi pula. Namun, secara alami perubahan mutu kesegaran ikan dan lainnya yang dapat terjadi secara enzimatis, kimia, dan bakteriologi sangat dipengaruhi oleh temperatur (Hasan, dkk., 2016). Pada temperatur ruang, hasil tangkapan laut akan lebih mudah rusak dibandingkan ketika disimpan pada temperatur yang rendah (Noor, dkk., 2019). 
Beberapa metode penyimpanan bahan pangan yang kerap digunakan diantaranya adalah melalui penggunaan bahan kimia, pengontrolan kandungan air, pengeringan, penggorengan, iradiasi, dan pembekuan (Sari \& Hadiyanto, 2013). Namun diantara berbagai metode tersebut, metode pembekuan pada temperatur hingga sekitar -1 sampai $-2^{\circ} \mathrm{C}$ merupakan metode yang paling potensial digunakan pada produk perikanan ketika produk tersebut akan kembali dijual atau dimanfaatkan dalam bentuk basah (Sanger, 2010; Meiriza, dkk., 2016). Hal ini dikarenakan, metode pembekuan tidak merusak kualitas organoleptik dan mudah untuk diaplikasikan.

\section{Metodologi Pelaksanaan}

Kegiatan pengabdian kepada masyarakat yang dilakukan di Desa Penyak, Kecamatan Koba, Kabupaten Bangka Tengah ini terdiri dari tiga tahapan yang meliputi: tahap persiapan, tahap pelaksanaan, dan tahap monitoring serta evaluasi.

\section{Tahap Persiapan}

Pada tahap persiapan dimulai dengan rapat koordinasi tim meliputi pengarahan dan pembagian penanggung jawab program kerja. Melalui rapat koordinasi awal ini, masing-masing pelaksana kegiatan pengabdian memiliki gambaran umum tentang hal-hal teknis yang perlu dilakukan saat kegiatan pengabdian. Kemudian dilanjutkan dengan survei lapangan di Desa Penyak untuk memastikan kesesuaian kegiatan pengabdian masyarakat dengan kondisi wilayah. Selain melakukan penyesuaian pada kegiatan ini juga akan dilakukan koordinasi dengan pihak desa, karang taruna, dan kelompok nelayan. Sehingga kerja sama serta penyelarasan program dengan pihak desa dapat berjalan dengan baik.

\section{Tahap Pelaksanaan}

Tahap pelaksanaan diawali dengan proses pembelian serta pemesanan alat dan bahan yang akan digunakan dalam kegiatan pengabdian kepada masyarakat terutama pemesanan alat penyimpanan beku yang disebut dengan freezer box. Setelah itu juga disusun materi/bahan untuk kegiatan pengabdian kepada masyarakat baik dalam bentuk bahan presentasi maupun poster yang terkait dengan hasil tangkapan laut, penyimpanan, serta pengolahan-pengolahannya.

Pelaksanaan kegiatan pengabdian kepada masyarakat diselenggarakan bersama dengan perangkat desa, karang taruna, serta kelompok nelayan. Secara umum kegiatan pengabdian yang dilaksanakan berupa kegiatan sosialisasi/penyuluhan terkait dengan metode-metode penyimpanan produk hasil kelautan serta metode-metode pengolahannya yang kemudian diikuti dengan penyerahan/transfer teknologi tepat guna berupa peralatan freezer box.

\section{Monitoring dan Evaluasi}

Kegiatan monitoring dan evaluasi pada pengabdian kepada masyarakat ini dilakukan melalui diskusi dengan aparatur Desa Penyak terkait pemanfaatan dan pengecekan kondisi alat freezer box yang telah diberikan.

\section{Hasil dan Pembahasan}

Tahapan persiapan diawali dengan melakukan kegiatan survei lapangan yang dilaksanakan sekitar bulan Mei 2018 oleh tim pengabdian kepada masyarakat yang secara langsung meninjau kondisi lokasi di desa Penyak seperti pada Gambar 2. Selain itu, tim pengabdian kepada masyarakat juga melakukan diskusi dengan aparatur desa dan masyarakat sekitarnya. Berdasarkan hasil survei dan diskusi dengan aparat perangkat desa didapatkan beberapa permasalahan. Salah satu permasalahan yang dimiliki oleh masyarakat Desa Penyak yang mayoritas mata pencahariannya sebagai nelayan yaitu tidak semua nelayan memiliki pengetahuan mengenai proses dan metode metode pengawetan produk hasil laut misalkan melalui proses pembekuan supaya kualitas hasil tangkapan tetap terjaga. Didasarkan pada permasalahan yang ada maka akan dilakukan sosialisasi 
terkait metode pendinginan untuk menyimpan hasil tangkapan laut bagi masyarakat di Desa Penyak menggunakan freezer box.

Setelah diperoleh gambaran permasalahan dan solusi secara utuh selanjutnya tim pengabdian kepada masyarakat melakukan koordinasi dengan aparatur desa terkait dengan jadwal dan tempat pelaksanaan sosialisasi. Setelah diperoleh kesepakatan waktu dan tempat pelaksaan selanjutnya aparatur Desa Penyak menyebarkan undangan kepada masyarakat di Desa Penyak terutama bagi kalangan nelayan, penjual produk hasil tangkapan laut, serta Badan Usaha Milik Desa Penyak.

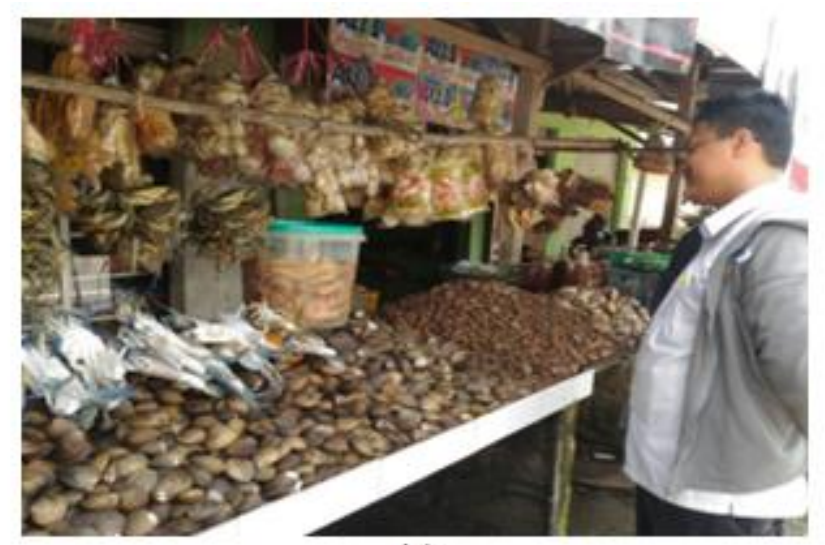

(a)

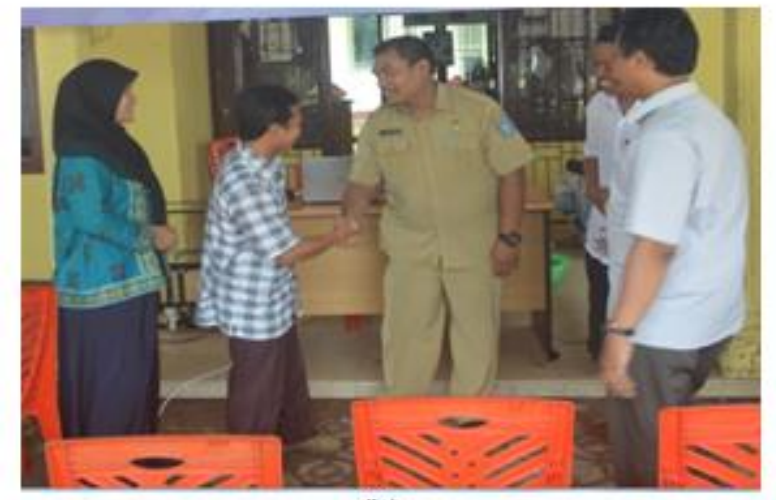

(b)

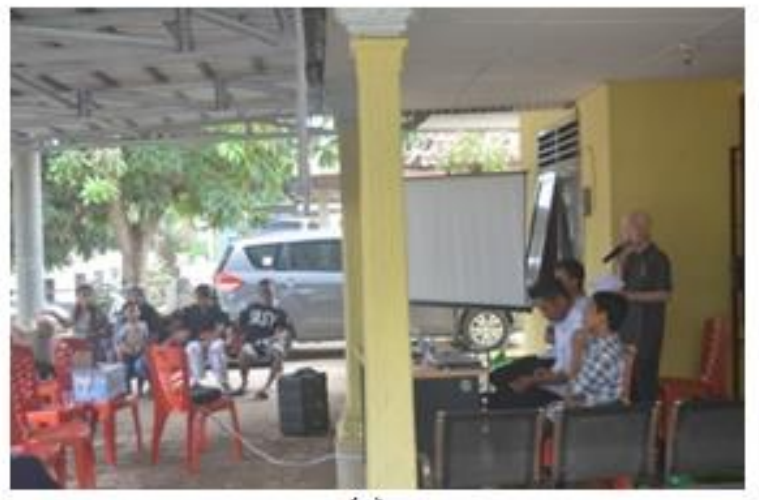

(c)

Gambar 2. Tahapan persiapan pengabdian kepada masyarakat: (a) observasi dan wawancara dengan penjual hasil tangkapan laut di Desa Penyak, (b) pertemuan dengan aparatur desa, dan (c) diskusi dengan masyarat di Desa Penyak

Pelaksanaan kegiatan pengabdian kepada masyarakat ini dilakukan pada 14 November 2018 bertempat di Kantor Desa Penyak. Sesuai dengan undangan dari pihak Desa Penyak, kegiatan ini diikuti oleh berbagai kalangan masyarakat Desa Penyak dan para aparatur desa dengan peserta sekitar 20-an orang. Pelaksanaan kegiatan pengabdian kepada masyarakat ini dilakukan dengan metode ceramah, diskusi, tanya jawab secara langsung, serta contoh kasus. Peserta sosialisasi mendapat informasi dari para pemateri terkait teknik dan metode penyimpanan beku, produk olahan hasil tangkapan laut, serta cara penggunaan dan perawatan freezer box seperti pada Gambar 3. Selain itu, sebagai penutup pelaksaan kegiatan pengabdian masyarakat dilakukan penyerahan alat freezer box bagi Desa Penyak (Gambar 4) yang diikuti oleh penandatangan berita acara serah terima (Gambar 5). Kegiatan pengabdian kepada masyarakat ini mendapat sambutan yang baik dari masyarakat di Desa Penyak. Hal ini terlihat dari keaktifan masyarakat untuk terlibat dalam kegiatan diskusi dan dalam praktik penggunaan peralatan yang diberikan. 


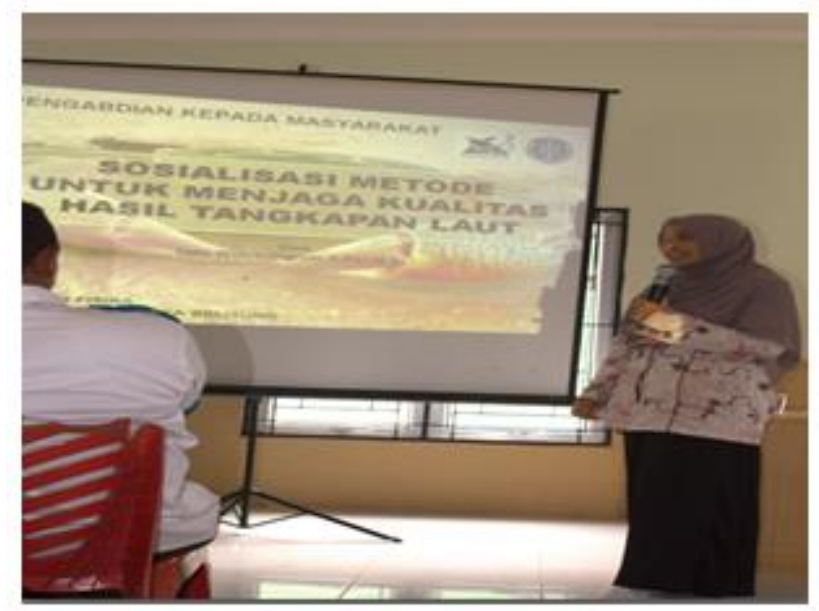

Gambar 3. Penyampaian salah satu materi sosialisasi oleh tim pengabdian kepada masyarakat

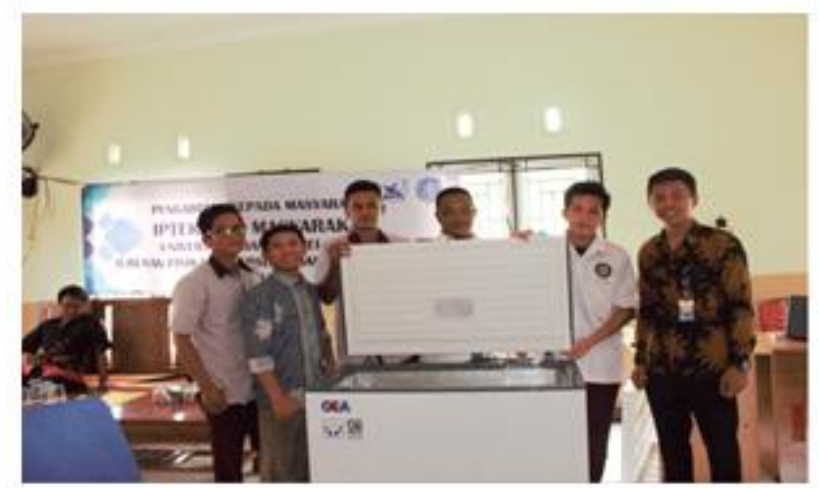

Gambar 4. Penyerahan Alat Freezer Box kepada Masyarakat Desa Penyak

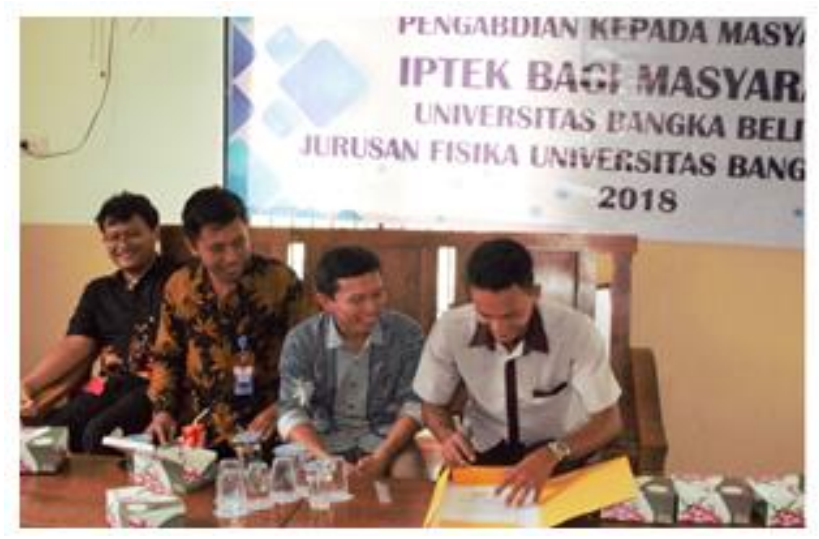

Gambar 5. Penandatanganan Berita Acara antara Pihak Desa Penyak dengan Jurusan Fisika Universitas Bangka Belitung.

Untuk menjamin alat freezer box yang diberikan kepada pihak Desa Penyak dapat termanfaatkan dengan baik maka tim pengabdian kepada masyarakat melakukan kunjungan kembali untuk melakukan evaluasi. Kunjungan dilakukan pada waktu setahun setelah pelaksanaan sosialisasi. Melalui hasil diskusi dan tinjauan di lapangan diperoleh informasi bahwa peralatan freezer box yang diserahkan kepada Desa Penyak dapat beroperasi dengan baik dan dimanfaatkan oleh pihak Desa Penyak melalui Badan Usaha Milik Desa untuk menyimpan berbagai produkproduk olahan pangan yang dihasilkan. 


\section{Ucapan Terima Kasih}

Penelitian ini didanai oleh Universitas Bangka Belitung melalui skema Pengabdian Dosen Tingkat Jurusan tahun 2018 (PMTJ UBB 2018).

\section{Daftar Pustaka}

Auliya, C., Woro, O., \& Budiono, I. (2015). Profil status gizi balita ditinjau dari topografi wilayah tempat tinggal (studi di wilayah pantai dan wilayah punggung bukit kabupaten jepara). Unnes Journal of Public Health, 4(2), 108-116.

Darmadi, B., Sulistiyowati, W., Sofijanto, M., \& Riando, B. (2016). Pemberdayaan UKM pengolah ikan melalui aplikasi coldchain system pada produksi ikan olahan bersertifikasi di Kecamatan PAciran, Kabupaten Lamongan, Jawa Timur. Seminar Nasional Hasil Penelitian dan Pengabdian Kepada Masyarakat (pp. 1-12). Denpasar: LPPM UNMAS Denpasar.

Hasan, B., Desmelati, Iriani, D., Sumarto, \& Sahyudi. (2016). Evaluasi karakterisasi fisikokimia baung asap yang dibuat dari ikan segar dan beku. Jurnal Pengolahan Hasil Perikanan Indonesia, 19(2), 121-131.

Meiriza, Y., Dewi, E., \& Rianingsih, L. (2016). Perbedaan karakteristik ikan bandeng (Chanos chanos forsk) cabut duri dalam kemasan berbeda selama penyimpanan beku. J. Peng. \& Biotek. Hasil Pi., 5(1), 36-43.

Noor, A., Evi, J., Mustari, Safitri, A. D., Afriani, A., \& Tiandho, Y. (2019). Senduduk (Melastoma malabathricum L.) extract as a green-indicator for monitoring shrimp freshness. Advances in Engineering Research, 167, 167-169.

Nugroho, T., Kiryanto, \& Adietya, B. (2016). Kajian eksperimen penggunaan media pendingin ikan berupa es basah dan ice pack sebagai upaya peningkatan performance tempat penyimpanan ikan hasil tangkapan nelayan. Jurnal Teknik Perkapalan, 4(4), 889-898.

Sanger, G. (2010). Mutu kesegaran ikan tongkol (Auxis tazard) selama penyimpanan dingin. Warta WIPTEK, 35, 39-43.

Sari, D., \& Hadiyanto. (2013). Teknologi dan metode penyimpanan makanan sebagai upaya memperpanjang shelf life. Jurnal Aplikasi Teknologi Pangan, 2(2), 52-59. 